\title{
Vegetation Database of Great Britain: Countryside Survey
}

\author{
Lindsay Maskell, Simon Smart, Lisa Norton \& Claire Wood
}

\begin{abstract}
This paper describes the vegetation database created as part of the Countryside Survey (CS) of Great Britain (GIVD ID EUGB-003) which was established to monitor ecological and land use change in 1978 (http://www.countrysidesurvey.org.uk). The sample design is based on a series of stratified, randomly selected $1 \mathrm{~km}$ squares, which numbered 256 in the 1978 survey, 500 in the 1990 survey, 569 in the 1998 survey and 591 in the 2007 survey. Stratification of sample squares was based on predefined strata (called land classes) which have been derived from a classification of all $1 \mathrm{~km}$ squares in Britain based on their topographic, climatic and geological attributes obtained from published maps. A series of vegetation plots were located within each $1 \mathrm{~km}$ square using a restricted randomisation procedure designed to reduce aggregation. Linear features (road verges, watercourse banks, hedges, arable margins and field boundaries) and areal features (fields, unenclosed land and small semi-natural biotope patches) were sampled. Linear plots were $1 \times 10 \mathrm{~m}$ laid out along a feature whilst unenclosed land and small biotopes were sampled using $2 \mathrm{~m} \times 2 \mathrm{~m}$ plots. Larger randomly-placed plots were nested $14 \mathrm{~m}^{2}$ plots with an inner nest of $2 \mathrm{~m} \mathrm{x} 2 \mathrm{~m}$. Within each $1 \mathrm{~km}$ Countryside Survey sample square the land cover and all landscape features were mapped and each parcel of land (and vegetation plot) has been assigned to a Broad Habitat/EUNIS habitat type. This database of vegetation plots is a very useful resource. The data is freely available from the website, however, there are restrictions on the release of the spatial location of the plots. There is now a considerable time-series of plots within the database going back to 1978 representing different habitat types and landscape features that can be analysed to determine changes in vegetation metrics (e.g. Ellenberg scores) and individual species. Vegetation changes can be linked to environmental drivers and the spatial scale (across GB) is sufficiently large to analyse gradients in most driving variables.
\end{abstract}

Keywords: driver; monitoring; random sample.

\section{Vegetation Database of Great Britain: Countryside Survey}

Scope: CS samples stratified, randomly selected $1 \mathrm{~km}$ squares, 256 in the 1978 survey, 500 in the 1990 survey, 569 in the 1998 survey and 591 in the 2007 survey. A series of vegetation plots were located within each $1 \mathrm{~km}$ square. Linear features (road verges, watercourses, hedges, arable margins and field boundaries) and areal features (fields) were sampled. Linear plots were $1 \times 10 \mathrm{~m}$ small biotopes - $2 \mathrm{~m} \times 2 \mathrm{~m}$ plots. Larger randomly-placed plots were nested $14 \mathrm{~m}^{2}$ plots with an inner nest of $2 \mathrm{~m} \times 2 \mathrm{~m}$.

Status: completed and continuing

Period: $1978-2007$

Database manager(s): Claire Wood (clamw@ceh.ac.uk)

Owner: Defra/Natural Environment Research Council

Web address: http://www.countrysidesurvey.org.uk/

Availability: free online

Database format(s): Oracle

Online upload: yes

Online search: yes UK Headline Messages from 2007. NERC/Centre for Ecology \& Hydrology, 30pp. (CEH Project Number: C03259).

Plot type(s): normal plots; nested plots; time series

Plot-size range: $2-200 \mathrm{~m}^{2}$

Non-overlapping plots: 49,165

Estimate of existing plots: 49,165

Number of sources: 1

Completeness: $100 \%$

Total plot observations: 58,698

Number of sources: 1

Valid taxa: 1,512

Countries: GB: $100.0 \%$

Forest: [NA] — Non-forest: [NA]

Guilds: all vascular plants: $100 \%$; bryophytes (terricolous or aquatic): $70 \%$; lichens (terricolous or aquatic): $20 \%$

Environmental data: slope aspect: $80 \%$; slope inclination: $80 \%$; soil depth: 100\%; surface cover other than plants (open soil, litter, bare rock etc.) $30 \%$; soil pH: $30 \%$

Performance measure(s): cover: $100 \%$; number of individuals: $100 \%$

Geographic localisation: political units or only on a coarser scale (>10 km): $100 \%$

Sampling periods: $1970-1979$ : $6.0 \%$; $1990-1999: 57.0 \% ; 2000-2009: 36.0 \%$

Information as of 2012-07-12; further details and future updates available from http://www.givd.info/ID/EU-GB-003

Lindsay Maskell* (lcma@ceh.ac.uk), Simon Smart (ssma@ceh.ac.uk), Lisa Norton (lrn@ceh.ac.uk), Claire Wood (clamw@ceh.ac.uk) Land Use Research, Centre for Ecology and Hydrology, Library Avenue, LA1 4AP Lancaster, UNITED KINGDOM

*Corresponding author 